\title{
Achieving Portfolio Diversification through Cryptocurrencies in European Markets
}

\author{
Ana Pavković, Mihovil Anđelinović, Ivan Pavković \\ University of Zagreb, Faculty of Economics and Business, Zagreb, Croatia
}

\section{Abstract}

Background: Cryptocurrencies represent a specific technological innovation in financial markets that keeps getting more and more popular among investors around the world. Given the specific characteristics of the cryptocurrencies, this paper examines the possibility of their use as a diversification instrument. Objectives: This paper examines the direction and strength of the relationship between the selected cryptocurrencies and important financial indicators on the European Union market. Since cryptocurrencies are a novelty in the financial system, the empirical literature in this area is rather scarce. Methods/Approach: In order to assess diversification properties of cryptocurrencies for European traders, a comprehensive econometric analysis was carried out. The first part of the analysis refers to the estimation of the multivariate Generalized Autoregressive Conditional Heteroskedasticity (GARCH) model, whereas the second part focuses on wavelet transforms. Results: Bitcoin and Ripple proved as a possible diversification instrument on most of the observed European markets since corresponding coefficients of unconditional correlation are negative. Conclusions: The relationship between the value of the cryptocurrencies and selected indices is generally very weak and slightly negative, indicating that some cryptocurrencies can serve as a means of diversification. However, investors need to take into account the extreme volatility, exhibited in all existing cryptocurrencies.

Keywords: Bitcoin, portfolio diversification, volatility clustering, wavelet, cryptocurrencies

JEL classification: G1 1, C32, F31, C58

Paper type: Research article

Received: Oct 02, 2018

Accepted: Feb 03, 2019

Citation: Pavković, A., Anđelinović, M., Pavković, I. (2019), "Achieving Portfolio Diversification Through Cryptocurrencies in European Markets", Business Systems Research, Vol. 10, No. 2, pp. 85-107.

DOI: $10.2478 /$ bsrj-2019-020

\section{Introduction}

In recent years, cryptocurrencies have experienced strong growth in terms of market capitalization expansion, but also in terms of popularity and significance. Due to their specific and technologically innovative form, they attract the interests of a large number of investors around the world. This trend applies to European Union investors as well, who recognize the opportunity for potential profit and diversification of their portfolio. The main objective of this paper is to analyse cryptocurrencies as a potential instrument for portfolio diversification of investors investing in European markets. In 
other words, this study analyses the correlation between selected cryptocurrencies and the most significant financial indicators on the European market to see if investors could enhance the efficiency of their portfolios. The starting hypothesis of this study is that cryptocurrencies advance the diversification of European investors' portfolios. This paper aims to contribute to the empirical literature that studies cryptocurrencies by providing a comprehensive study of European stock markets.

The remainder of this paper is structured as follows. First section explains the development of cryptocurrencies and presents relevant literature. The second section describes the dataset and methodology. The third section presents our findings and comments on the limitations of this research. The last section concludes.

\section{The Cryptocurrencies Phenomenon}

By providing an alternative form of money and an alternative form of investment, cryptocurrencies function outside of the financial institutions. They offer their investors an inexpensive alternative to traditional currencies in terms of transaction costs but, as a consequence, the prices change very quickly. It is important to note that the investment in cryptocurrencies is of high risk and has a speculative character, which means such investments should be made with a precaution (European Commission, 2018).

The emergence of cryptocurrencies causes certain conflicts in the political and financial system. The world's largest cryptocurrency is called Bitcoin, explained as a peer-to-peer version of digital money that allows making transactions via the internet without the intermediary role of financial institutions (Poyser, 2017). The first Bitcoin was created on 3 January 2009 and had been growing rapidly since, owing to its simple use as a form of payment. Of course, due to the lack of regulation and absence of legal measures against this cryptocurrency, it's being used in the illegal trade of goods and services. However, the emergence of this cryptocurrency can also be considered as the consequence of the financial crisis.

The success of Bitcoin has prompted the development of new cryptocurrencies, popularly referred to as Altcoin. Some of the first Altcoin to appear were Litecoin, PeerCoin, AuroraCoin, and Ripple, who used the existing Bitcoin technology but have slightly improved it. With these new, smaller and decentralized digital currencies without a monetary base, the price fluctuates far more significantly than the standard fiat currencies, such as the US dollar and the Euro (European Commission, 2018).

Bitcoin has become the 'gold' standard among cryptocurrencies since it is the most widely accepted in commerce, has the largest mining network, and the greatest volume of transactions. Alternate cryptocurrencies have been developed to improve upon various technical and practical aspects of Bitcoin; however, despite the fact that it may be technologically inferior to various alternatives, it remains entrenched due to its path-dependency (Hayes, 2015).

Many authors like Tillier (2015) point to the importance of regulating cryptocurrencies, as they are used in the exchange of goods and services. Yet some authors, like Penrose (2014), emphasizing that cryptocurrencies cannot be treated like traditional currencies since they do not satisfy the definition of a currency (Brière et al., 2015). Although there is no single, applicable, and standardized rule for cryptocurrencies in the European Union at this time, discussions are in progress. However, current directives for the financial market, such as MiFID and AIFMD, consumer protection, anti-money laundering (AML), and counter-terrorist financing directives are being considered. The European Central Bank (2012) (ECB), however, states that it is not their responsibility to prohibit or regulate the use of cryptocurrencies and that their role is to warn of potential risks that could stem from such investments. 
ECB defines cryptocurrencies as unregulated, digital money, which is issued and usually controlled by its developers, and used and accepted among the members of a specific virtual community (European Central Bank, 2012). There is normally no asset with intrinsic value underlying the virtual currency, nor is there any central bank backing the currency and acting as a lender of last resort. Cryptocurrencies cannot, therefore, be considered as safe money, considering the likelihood of the asset retaining its value for the holder, and hence its acceptability to others as a means of payment cannot be ensured (European Central Bank, 2018).

European Securities and Markets Authority (ESMA), European Banking Authority (EBA) and European Insurance and Occupational Pensions Authority (EIOPA) point to extreme price volatility, the absence of protection, lack of exit options and misleading information. It is necessary to understand the cryptocurrencies before making an investment. They also advise investors to invest only the money they are prepared to lose, as well as to safely store it to protect themselves from a cyber-attack (ESMA, 2018). Croatian Financial Services Supervisory Agency (Hanfa), is warning consumers on the high risks of buying and/or holding virtual currency as well, emphasizing that there is currently no cryptocurrency directive at the EU level (Croatian Financial Services Supervisory Agency, N/A).

\section{Literature Review}

A study by Brière et al. (2015) is one of the first to assess cryptocurrencies', or specifically Bitcoin's, diversification potential, compared to traditional currencies. Bitcoin is an attractive investment option due to the weak correlation, not only with traditional financial instruments but also with alternative investments. Kristoufek (2015) using Wavelet coherence analysis, concludes that fundamental economic factors determine the price of Bitcoin. Bouri et al. (2017a; 2017b) use dynamic correlation methods to explore Bitcoin's diversification potential for the world's most important indices, bonds, oil, gold, US dollars, and other traditional commodities. These three studies provide evidence that Bitcoin is not a safe long-term investment, but a combination of financial instruments and speculative "bubbles". Velde (2013) argues that Bitcoin, although without the backing of a central bank, follows the "rules" of the gold standard and rewards "miners" with digital money for solving complex mathematical problems. That paper inspired a recent study by Bouri et al. (2017c) where authors evaluate miners' profit using Wavelet-based quantile-in-quantile regressions, i.e., cost of energy that is used in solving these problems in relation to their revenue. Therefore, Bitcoin can be considered as an interesting asset for portfolio diversification purposes, owing to its link to commodities (Eisl, Gasser and Weinmayer, 2015; Halaburda and Gandal, 2016). Dhyrberg (2015) finds that Bitcoin can be used as a hedge against stocks in the Financial Times Stock Exchange Index. Additionally, Bitcoin can be used as a hedge against the U.S. dollar in the short-term.

Katsiampa (2017) estimates the volatility of Bitcoin by comparing the results of the GARCH model and the AR-CGARCH model. Urquhart (2017) proves that HAR models are more robust in Bitcoin volatility modelling versus traditional GARCH models. Stavroyiannis and Babalos (2017) explored the dynamic components of Bitcoin modelling through univariate and multivariate GARCH models and VAR models. Aside from GARCH models, Lim and Masih (2017) also use Wavelet tools to determine the correlation between two-time series. Cermak (2017) employs a GARCH model to analyse Bitcoin's volatility with respect to the macroeconomic variables of countries where Bitcoin is being traded the most. The author finds that Bitcoin behaves similarly to fiat currencies in China, the U.S., and the European Union but not in Japan. Moreover, Bitcoin acts as a safe-haven asset in China (Chu et al., 2017). 
Turning to other cryptocurrencies, Halaburda and Gandal (2016) examined competition among many smaller cryptocurrencies. They argue that arbitration options are virtually unavailable and express the value of Altcoin in US Dollar, instead of Bitcoin. It is important to point out that these smaller cryptocurrencies appear more efficient and less volatile when their value is in Bitcoin. In European Commission (2018), Altcoins' price movements are compared with Bitcoin. The study examines sixteen most popular Altcoins in the period of 3 years. They inferred that Bitcoin could have a major impact on them in the short run, however, not in the long term. The value of Altcoins, but also of Bitcoin, is almost unpredictable in the long run and is largely dependent on the supply and demand for a particular cryptocurrency.

\section{Methodology}

Multivariate GARCH models are often used in financial research, where the clustered variance is assumed, i.e., where there are tranquil periods on the one hand and periods of frequent changes on the other. As mentioned above, GARCH models are often used in studies on cryptocurrencies due to high volatility. To the contrary, the Wavelet approach enables the identification of capital market interactions that can be challenging with any other time-series method (Lim and Masih, 2017).

\section{Multivariate GARCH - Dynamic Conditional Correlation}

MGARCH-DCC modelling enables an analysis of precise timings of a shift in conditional correlations and volatilities. The main advantage of the dynamic conditional correlation model (DCC) compared to other similar models is that it involves changes in both the first and second moments, i.e., mean and variance of time series. Estimation of the MGARCH-DCC model includes two steps in order to simplify the estimation of time-varying correlations. Firstly, univariate volatility parameters are estimated, and then standardized residuals from the first step are used as inputs for estimating a time-varying correlation matrix (Lim and Masih, 2017).

The probability used in the first step involves the substitution of $R_{t}$ with $I_{k}$, an identity matrix size $k$. If model parameters $\theta$ are denoted in two groups $\left(\varphi_{1}, \varphi_{2}, \ldots, \varphi_{k}, \psi\right)=(\varphi, \psi)$, where $\varphi_{i}$ correspond to parameters of univariate GARCH model for $i$-th part of asset series, $\varphi_{i}=\left(\omega, a_{1 i}, \ldots, a_{i i}, \beta_{1 i}, \ldots, \beta_{Q i i}\right)$, the first step is then denoted:

$$
\begin{aligned}
Q L_{1}\left(\varphi \mid r_{t}\right)=- & \frac{1}{2} \sum_{t=1}^{T}\left(k \log (2 \pi)+\log \left(\left|I_{k}\right|\right)+2 \log \left(\left|D_{t}\right|\right)+r^{\prime}{ }_{t} D^{-1}{ }_{t} I_{k} D^{-1}{ }_{t} r_{t}\right) \\
= & -\frac{1}{2} \sum_{t=1}^{T}\left(k \log (2 \pi)+2 \log \left(\left|D_{t}\right|\right)+r^{\prime}{ }_{t} D^{-2}{ }_{t} r_{t}\right) \\
& =-\frac{1}{2} \sum_{t=1}^{T}\left(k \log (2 \pi)+\sum_{n=1}^{k}\left(\log \left(h_{i t}\right)+\frac{r^{2}{ }_{i t}}{h_{i t}}\right)\right) \\
& =-\frac{1}{2} \sum_{n=1}^{k}\left(T \log (2 \pi)+\sum_{t=1}^{T}\left(\log \left(h_{i t}\right)+\frac{r^{2}{ }_{i t}}{h_{i t}}\right)\right) .
\end{aligned}
$$


This is the sum of the log-likelihoods of the individual GARCH equations for the assets. Once the first stage has been estimated, the second stage is estimated using the correctly specified likelihood, conditioning on the parameters estimated in the first stage likelihood:

$$
\begin{aligned}
& Q L_{2}\left(\psi \mid \hat{\varphi}, r_{t}\right)=-\frac{1}{2} \sum_{t=1}^{T}\left(k \log (2 \pi)+2 \log \left(\left|D_{t}\right|\right)+\log \left(\left|R_{t}\right|\right)\right. \\
& \left.\quad+r_{t}^{\prime}{ }_{t} D^{-1}{ }_{t} R^{-1}{ }_{t} D^{-1}{ }_{t} r_{t}\right) \\
& =-\frac{1}{2} \sum_{t=1}^{T}\left(k \log (2 \pi)+2 \log \left(\left|D_{t}\right|\right)+\log \left(\left|R_{t}\right|\right)+\varepsilon^{\prime}{ }_{t} R^{-1}{ }_{t} \varepsilon_{t}\right) .
\end{aligned}
$$

Given the condition $\hat{\varphi}$, the only part of the observed function that affects the choice of parameters is $\log \left(\left|R_{t}\right|\right)+\varepsilon^{\prime}{ }_{t} R^{-1}{ }_{t} \varepsilon_{t}$ (Engle and Sheppard, 2001), so it is easier to exclude constants and maximize:

$$
Q L_{2}{ }^{*}\left(\psi \mid \hat{\varphi}, r_{t}\right)=-\frac{1}{2} \sum_{t=1}^{T}\left(\log \left(\left|R_{t}\right|\right)+\varepsilon^{\prime}{ }_{t} R^{-1}{ }_{t} \varepsilon_{t}\right) .
$$

DCC model, according to Engle (2002) and Tse et al. (2002) is defined as:

$$
H_{t}=D_{t} R_{t} D_{t}
$$

where $H_{t}$ is conditional variance matrix, $D_{t}$ diagonal matrix of conditional time varying standardized residuals and $R_{t}$ time varying correlation matrix. $D_{t}$ is defined in:

$$
D_{t}=\operatorname{diag}\left(h^{\frac{1}{2}} 11 t \ldots h^{\frac{1}{2}} N N t\right) \text {, }
$$

where $h_{i i t}$ can be defined as any univariate GARCH model and:

$$
R_{t}=\left(1-\theta_{1}-\theta_{2}\right) R+\theta_{1} \psi_{t-1}+\theta_{2} R_{t-1}
$$

where $\theta_{1}$ and $\theta_{2}$ are non-negative parameters satisfying $\theta_{1}+\theta_{2}<1, R$ is a symmetric $N \times N$ positive definite parameter matrix with $p_{i i}=1$ and $\psi_{t-1}$ is $N \times N$ correlation matrix of $\varepsilon_{t}$ for $\tau=\mathrm{t}-\mathrm{M}, \mathrm{t}-\mathrm{M}+1, \ldots, \mathrm{t}-1$ (Bauwens et al., 2006).

\section{Wavelet transform}

Wavelet approach is employed to overcome non-stationarity of the series signals and for analysing financial relations, especially when there is a distinction between short and long-run relations. Furthermore, Wavelets are localized in both time and scale (frequency band) and can be used to decompose any observed variable on the scale by scale (different frequency bands) basis in order to analyse the dynamics of co-movement across different time horizons without, information loss (Lim and Masih, 2017).

For the explanation of the concept of time-frequency analysis, Fourier transforms are the most commonly used. Fourier's order denotes a function with sinuses and cosines. For function $f$ with period $T=b-a$ equals:

$$
f(x)=\frac{a_{0}}{2}+\sum_{n=1}^{\infty}\left(\alpha_{n} \sin \left(\frac{2 n \pi x}{T}\right)+b_{n} \cos \left(\frac{2 n \pi x}{T}\right)\right),
$$

where $a_{n}$ and $b_{n}$ are given by integrals: 


$$
\begin{gathered}
a_{0}=\frac{2}{T} \int_{a}^{b} f(x) d x \\
a_{n}=\frac{2}{T} \int_{a}^{b} f(x) \cos \frac{2 n \pi x}{T} d x, n \geq 1 \\
b_{n}=\frac{2}{T} \int_{a}^{b} f(x) \sin \frac{2 n \pi x}{T} d x, n \geq 1 .
\end{gathered}
$$

If the function is infinite, a continuous form of Fourier transform is required:

$$
F(s)=\int_{-\infty}^{+\infty} f(t) e^{-2 \pi i s t} d t
$$

This transform converts the signal or the function in the time domain into a notation in the frequency domain. This provides information about the record of the given function with the help of sine waves, which indicates the frequency and intensity. It should be noted that the information on the time of the individual frequency is lost. Therefore, for analysis of a stationary or periodic signal, Fourier transform is sufficient. If both information on intensity and time is needed, then time-frequency analysis should be used. Relying on the Heisenberg principle of ambiguity, it is not possible to know all the frequency and all the time components at the same time, but it is possible to find out a certain time frame frequency range. In this case, Gabor's transform is employed, which is actually short-time Fourier transformation (STFT). It is expressed by:

$$
G[f](t, \omega)=\tilde{f}_{g}(t, \omega)=\int_{-\infty}^{+\infty} f(\tau) g(\tau-t) e^{i \omega \tau} d \tau .
$$

This integral is a convolution of the observed signal with the spectrum, and when the function is excluded from the transform expression, Fourier's transformation of the function is obtained (Hajba, 2009):

$$
\psi_{a, b}=\frac{1}{\sqrt{a}} \psi\left(\frac{t-b}{a}\right)
$$

where $a$ and $b$ are real numbers, and $a \neq 0$. Discrete Wavelet Transform is defined as:

$$
\psi_{m, n}=a_{0}^{\frac{m}{2}} \psi\left(a_{0}^{-m} x-n b_{0}\right)
$$

where $a_{0}, b_{0}>0$, and $\mathrm{m}$ and $\mathrm{n}$ are integers. Complete Discrete Wavelet Transform is defined by:

$$
W_{\psi}[f](m, n)=\left(f, \Psi_{m, n}\right)=a_{0}^{\frac{m}{2}} \int_{-\infty}^{+\infty} f(t) \bar{\psi}\left(a_{0}^{-m} t-n b_{0}\right) d t .
$$

In most cases signal's length is $2 \mathrm{j}$ points, which provides the best results of Discrete Wavelet Transform. All transforms are given by: 


$$
(T f)(\omega, t)=\int_{t} K(t, \omega) f(t) d t
$$

where $K(t, \omega)$ is the core of the transform. The core of Fourier the transform is given by $e^{i \omega \tau}$, and the expression Continuous Wavelet Transform follows:

$$
W_{\psi}[f](a, b)=\left(f, \Psi_{a, b}\right)=\int_{-\infty}^{+\infty} f(t) \bar{\Psi}_{a, b}(t) d t
$$

and the main constraint is given by the constraint on constant $C_{\psi}=\int_{-\infty}^{+\infty} \frac{|\widehat{\psi}(\omega)|^{2}}{|\omega|} d \omega<\infty$ (Hajba, 2009).

\section{Results}

By employing MGARCH-DCC and Wavelet methods, this paper examines the correlation between the observed time series and cryptocurrencies role in enhancing the efficiency of an investor's portfolio. Basic characteristics of the time series are given in Table 1.

Table 1

\begin{tabular}{|c|c|c|c|c|c|}
\hline Variable & Mean & Median & Minimum & Maximum & $\begin{array}{l}\text { Standard } \\
\text { Deviation }\end{array}$ \\
\hline btc & 0.002877 & 0.001107 & -0.371564 & 0.308301 & 0.046537 \\
\hline eos & 0.002817 & -0.002553 & -0.356675 & 0.355890 & 0.102722 \\
\hline eth & 0.004334 & 0.000000 & -0.313422 & 0.258599 & 0.064289 \\
\hline Itc & 0.004511 & -0.000900 & -0.307951 & 0.606981 & 0.071026 \\
\hline xrp & 0.002783 & 0.000000 & -2.407946 & 2.302585 & 0.180460 \\
\hline cac_40 & 0.000269 & 0.000000 & -0.083844 & 0.046411 & 0.008358 \\
\hline crobex & 0.000193 & 0.000000 & -0.031112 & 0.033894 & 0.004171 \\
\hline dax & 0.000211 & 0.000000 & -0.070673 & 0.048521 & 0.008234 \\
\hline euronext & 0.000259 & 0.000000 & -0.069584 & 0.040105 & 0.007530 \\
\hline ftse_100 & 0.000204 & 0.000000 & -0.035192 & 0.035150 & 0.006235 \\
\hline gold_futures & -0.000225 & 0.000000 & -0.065976 & 0.046026 & 0.007342 \\
\hline oil_brent & 0.000238 & 0.000000 & -0.088574 & 0.104162 & 0.014412 \\
\hline smi & 7.49E-05 & 0.000000 & -0.090703 & 0.033658 & 0.006742 \\
\hline Variable & Skewness & Kurtosis & Jarque-Bera & Sum & Observations \\
\hline btc & -0.601166 & 13.11701 & 10124.78 & 6.733949 & 2341 \\
\hline eos & 0.404566 & 5.244879 & 86.36165 & 1.025561 & 364 \\
\hline eth & 0.004290 & 5.815401 & 278.4204 & 3.653914 & 843 \\
\hline Itc & 2.058036 & 16.62907 & 5709.200 & 3.049100 & 676 \\
\hline xrp & -1.339893 & 83.16619 & 334289.5 & 3.470578 & 1247 \\
\hline cac_40 & -0.353571 & 11.81230 & 7623.533 & 0.628667 & 2341 \\
\hline crobex & -0.332844 & 13.57547 & 10947.67 & 0.451626 & 2341 \\
\hline dax & -0.279729 & 9.414185 & 4043.567 & 0.494787 & 2341 \\
\hline euronext & -0.284554 & 10.81775 & 5993.074 & 0.605308 & 2341 \\
\hline ftse_100 & -0.009451 & 8.860971 & 3350.686 & 0.476906 & 2341 \\
\hline gold_futures & -0.333538 & 11.92792 & 7818.241 & -0.527174 & 2341 \\
\hline oil_brent & 0.512196 & 11.27827 & 6786.865 & 0.556630 & 2341 \\
\hline smi & -1.488404 & 23.78887 & 43019.65 & 0.175295 & 2341 \\
\hline
\end{tabular}

Basic Descriptive Statistics for Variables

Source: Authors' work using EViews 10 
Top five cryptocurrencies are chosen according to their market capitalisation value. On 30 June 2018, last day of the research period, the market capitalisation of Bitcoin was approximately $\$ 106$ billion, of Ethereum $\$ 43$ billion, of Ripple $\$ 17$ billion, of EOS $\$ 6$ billion, and of Litecoin $\$ 4$ billion. Beginning of the research period for Bitcoin is 2 February 2012, for Ripple 1 February 2015, for Litecoin 11 March 2016, for Ethereum 25 August 2016 and for EOS 2 Jul 2017, whereas the research period ends with 30 June 2018. The analysis uses the logarithm of returns for normalisation purposes. Returns are calculated as differences of the logarithmic daily closing prices: $\left\{\ln \left(p_{t}\right)-\ln \left(p_{t-1}\right)\right\}$.

The study also uses data on French capital market index CAC 40 (Cotation Assistée en Continu), Croatian Crobex, German index DAX (Deutscher Aktien index), Paneuropean index Euronext 100, British FTSE 100, Gold futures and Oil Brent futures, which are a proxy for gold and oil, as well as Swiss index SMI (Swiss Market Index). These indices reflect European capital market trends the best (CNN Money Stock Market Data, N/A). Zagreb Stock Exchange index is used to examine the Croatian market.

Volatility, measured by standard deviation, is extremely high in cryptocurrencies, and at the lowest level in Crobex. The most volatile cryptocurrency is Ripple (xrp) with a value of 0.180460, while Bitcoin (btc) has the smallest deviations among digital currencies. However, cryptocurrencies were not observed in the same period, which may be the reason why newer cryptocurrencies seem less stable. The cryptocurrencies are characterized by a significantly higher mean.

The asymmetry coefficient suggests that the distribution of the values of most of the observed indices are slightly negative asymmetric. Exceptions are EOS, Ethereum, Litecoin and oil, whose distribution are positively asymmetric. Since $\propto_{4}>3$, and $\kappa>0$ in all variables Leptokurtic distribution with higher peaks and fatter tails can be recognized. In other words, dthe istribution of variables are not Normal, which is common in high frequency time series. Cryptocurrencies, SMI and gold proxy, have the highest skewness, but since Ripple's standard deviation is the highest, it can be deemed as the riskiest investment.

The null hypothesis for the Jarque-Bera test of Normality is rejected for all variables, given that the test values are greater than the critical values of $\chi^{2}$ distribution with two degrees of freedom at the $5 \%$ and $1 \%$ significance levels respectively. Unusual values and volatility clustering can be observed in Figure 1. The first five graphs show cryptocurrencies, whereas the remainder refers to other variables in alphabetical order. Volatility clustering is manifested in longer time series, and less evident in case of newer currencies, so this phenomenon is tested in Table 2. Since data do not fit the Normal distribution, a GARCH(1,1) model with underlying Student distribution will be estimated (Arnerić, 2007). 
Figure 1

Evolution of Daily Returns of the Selected Cryptocurrencies and Indices
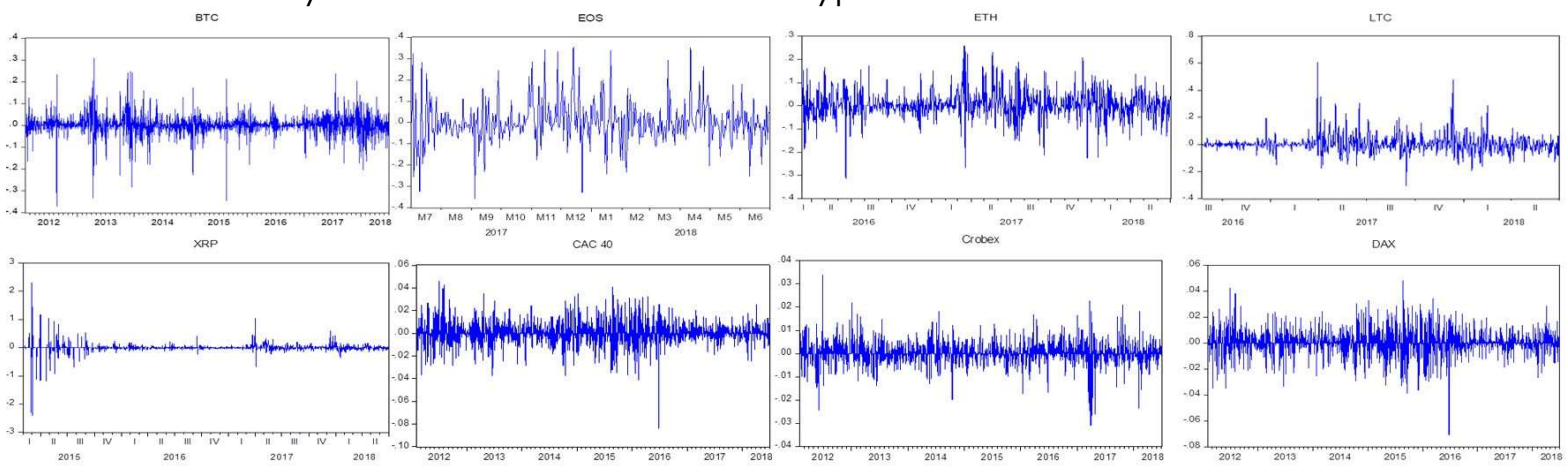

ELROTEXT

FTSE 100

GoL tutroes
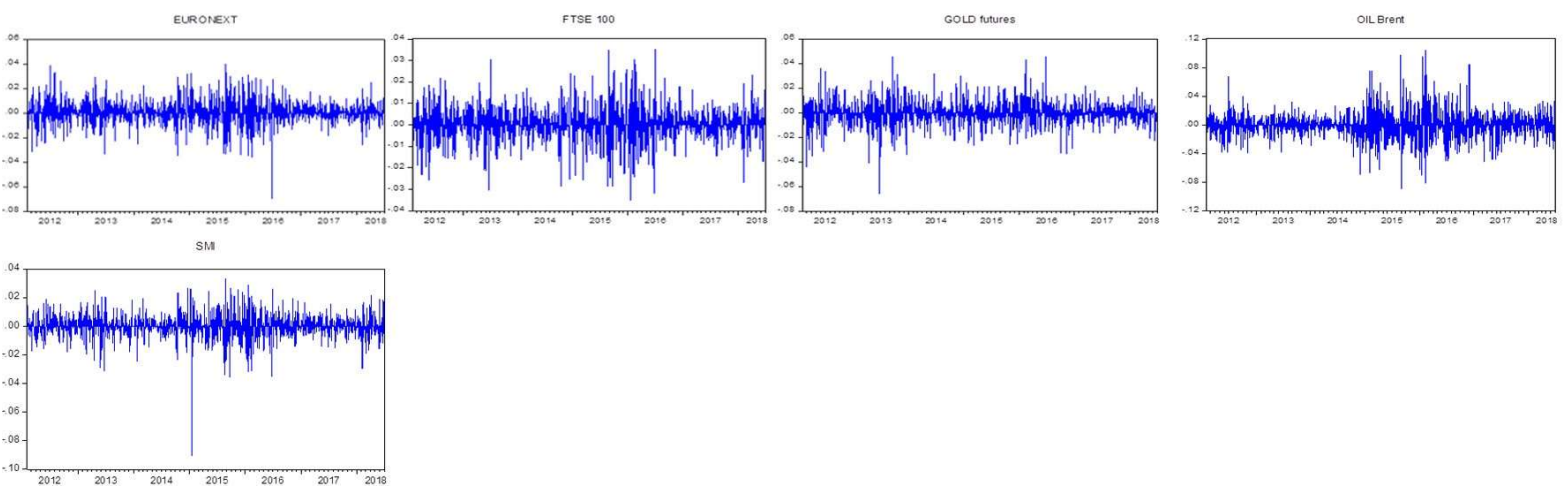

Source: Authors' work using EViews 10

\section{GARCH Model Estimation}

Before evaluating the GARCH model, several more diagnostic tests are performed. In order to define an adequate model, the unit root test is used to determine the stationarity of the process. Augmented Dickey-Fuller Test (ADF) is here used. Then it is necessary to test for the existence of the ARCH effect. Since ARCH and GARCH models are based on heteroskedasticity, the variances of the error terms have to be unequal. Lastly, autocorrelation and partial autocorrelation functions used to examine volatility. Correlograms for all of the variables pointed to non-significant empirical autocorrelation and partial autocorrelation functions. Test statistics, along with levels of significance of the remaining two tests are provided in Table 2.

Table 2

Unit Root and ARCH Effect Tests

\begin{tabular}{lll}
\hline Variable & ADF test (t-Statistic) & ARCH-LM test (F-Statistic) \\
\hline btc & $-48.33468^{* * *}$ & $304.0683^{* * *}$ \\
eos & $-19.72338^{* * *}$ & $2.812020^{*}$ \\
eth & $-28.92418^{* * *}$ & $70.25574^{* * *}$ \\
Itc & $-26.10542^{* * *}$ & $17.29719^{* * *}$ \\
\hline xrp & $-16.69373^{* * *}$ & $19.48513^{* * *}$ \\
cac_40 & $-49.81928^{* * *}$ & $17.55199^{* * *}$ \\
crobex & $-15.73102^{* * *}$ & $133.4965^{* * *}$ \\
dax & $-48.54771^{* * *}$ & $18.84573^{* * *}$ \\
euronext & $-49.05108^{* * *}$ & $23.39296^{* * *}$ \\
ftse_100 & $-49.49641^{* * *}$ & $89.87556^{* * *}$ \\
gold_futures & $-51.61004^{* * *}$ & 1.467387 \\
oil_brent & $-51.68995^{* * *}$ & $77.09742^{* * *}$ \\
smi & $-45.65133^{* * *}$ & $248.6767^{* * *}$ \\
\hline
\end{tabular}

Source: Authors' work using EViews 10

Note: ${ }^{* * *},{ }^{* *}$ and ${ }^{*}$ denote significance at $1 \%, 5 \%$ and $10 \%$ level respectively. 
As indicated in Table 2, the null hypothesis of non-stationarity of the time series is rejected, meaning that the series is stationary. The ARCH-LM test examines the variability of the residual variance. The null hypothesis of the mentioned test, which presupposes homoskedasticity, is rejected at a significance level of $1 \%$ or $10 \%$ for EOS, meaning that the variances do vary with the effects being modelled, so the variables are suitable for modelling the GARCH model. The exception is the gold_futures variable that does not show the existence of the ARCH effect and will therefore not be used in the GARCH model estimation, which does not, however, prevent the use of this variable in the time-frequency analysis. Table 3 provides the results of the multivariate GARCH-DCC model estimation for Bitcoin. Lambda 1 denotes beta, and lambda 2 alpha for each index, whereas delta 1 and delta 2 are beta and alpha for btc.

Table 3

MGARCH-DCC Model for Bitcoin with Underlying Student Distribution

\begin{tabular}{lllll}
\hline Parameter & Coefficient & Std. Error & †-value & Probability \\
\hline lambda1_cac_40 & 0.964244 & 0.022164 & 43.50 & 0.0000 \\
\hline lambda1_crobex & 0.972348 & 0.018204 & 53.42 & 0.0000 \\
lambda1_dax & 0.964286 & 0.014177 & 68.02 & 0.0000 \\
\hline lambda1_ftse_100 & 0.922907 & 0.042352 & 21.79 & 0.0000 \\
\hline lambda1_oil_brent & 0.961596 & 0.014179 & 67.82 & 0.0000 \\
\hline lambda1_smi & 0.886526 & 0.039547 & 22.42 & 0.0000 \\
\hline lambda2_cac_40 & 0.029245 & 0.016940 & 1.726 & 0.0845 \\
\hline lambda2_crobex & 0.018441 & 0.010481 & 1.759 & 0.0787 \\
lambda2_dax & 0.030943 & 0.013444 & 2.302 & 0.0215 \\
lambda2_ftse_100 & 0.056251 & 0.025577 & 2.199 & 0.0280 \\
\hline lambda2_oil_brent & 0.036879 & 0.012957 & 2.846 & 0.0045 \\
lambda2_smi & 0.088331 & 0.038509 & 2.294 & 0.0219 \\
delta1 & 0.955987 & 0.030610 & 31.23 & 0.0000 \\
delta2 & 0.003795 & 0.001504 & 2.524 & 0.0117 \\
Degrees of freedom & 2.220718 & 0.016365 & 135.7 & 0.0000 \\
No. Observations & 1644 & No. Parameters & & 66 \\
No. Series & 7 & Log Likelihood & & 44923.091 \\
\hline
\end{tabular}

Source: Authors' work using OxMetrics 6.20

Table 4 provides information on volatility and correlation. Coefficients of unconditional volatility are on the main diagonal, while the off-diagonals explain the unconditional correlations.

Table 4

Estimated Unconditional Volatility Matrix for Bitcoin

\begin{tabular}{cccccccc}
\hline & btc & cac_40 & crobex & dax & ftse_100 & $\begin{array}{c}\text { oil_ } \\
\text { brent }\end{array}$ & smi \\
\hline btc & $\mathbf{0 . 0 4 7 7 1 4}$ & 0.003827 & 0.004704 & -0.004895 & -0.010005 & -0.000010 & 0.002880 \\
cac_40 & 0.003827 & $\mathbf{0 . 0 1 0 3 2 4}$ & 0.352961 & 0.918163 & 0.864198 & 0.416775 & 0.847419 \\
crobex & 0.004704 & 0.352961 & $\mathbf{0 . 0 0 3 8 6 3}$ & 0.369035 & 0.352778 & 0.243267 & 0.365453 \\
\hline dax & -0.004895 & 0.918163 & 0.369035 & $\mathbf{0 . 0 1 0 2 3 7}$ & 0.854002 & 0.415743 & 0.856115 \\
ftse_100 & -0.010005 & 0.864198 & 0.352778 & 0.854002 & $\mathbf{0 . 0 0 6 9 7 2}$ & 0.453923 & 0.826086 \\
$\begin{array}{c}\text { oil_ } \\
\text { brent }\end{array}$ & -0.000010 & 0.416775 & 0.243267 & 0.415743 & 0.453923 & $\mathbf{0 . 0 2 1 0 5 5}$ & 0.372825 \\
smi & 0.002880 & 0.847419 & 0.365453 & 0.856115 & 0.826086 & 0.372825 & $\mathbf{0 . 0 0 8 1 7 9}$ \\
\hline
\end{tabular}

Source: Authors using OxMetrics 6.20 
The volatility parameters observed are highly significant with high t-ratio and volatility decay close to 1 for all currencies and indices. The sum of lambda 1 and lambda 2 that is beta and alpha is for all variables less than 1, meaning that shocks to the volatilities are not permanent, so IGARCH model is not required (Lim and Masih, 2017). Variable euronext is excluded since its univariate did not converge after a number of iterations.

Bitcoin is the most volatile with the unconditional volatility of 0.047714 , other variables being less volatile with coefficients in the range from 0.003863 (Crobex) to 0.021055 (oil proxy). Unconditional correlation coefficients are negative for btc with dax, euronext, and ftse_100, so it can make a diversification instrument. Oil proxy coefficient is negative as well, as Bouri et al. (2017a) inferred. A positive correlation can be seen in the case of French, Swiss, and Croatian indices, which means that a 'typical' investor in those markets does not 'benefit' from investing in Bitcoin. Table 5 and Table 6 present estimates for cryptocurrency EOS.

Table 5

MGARCH-DCC Model for EOS with Underlying Student Distribution

\begin{tabular}{lllll}
\hline Parameter & Coefficient & Std. Error & †-value & Probability \\
\hline lambda1_cac_40 & 0.926165 & 0.041420 & 22.36 & 0.0000 \\
lambda1_crobex & 0.895658 & 0.035713 & 25.08 & 0.0000 \\
\hline lambda1_dax & 0.947132 & 0.023698 & 39.97 & 0.0000 \\
lambda1_euronext & 0.916166 & 0.043866 & 20.89 & 0.0000 \\
\hline lambda1_smi & 0.719234 & 0.33994 & 2.116 & 0.0351 \\
\hline lambda2_cac_40 & 0.045616 & 0.025941 & 1.758 & 0.0795 \\
lambda2_crobex & 0.044216 & 0.030756 & 1.438 & 0.1514 \\
lambda2_dax & 0.040407 & 0.020696 & 1.952 & 0.0517 \\
lambda2_euronext & 0.057381 & 0.033714 & 1.702 & 0.0896 \\
lambda2_smi & 0.137698 & 0.094324 & 1.460 & 0.1452 \\
\hline delta1 & 0.837222 & 0.035882 & 23.33 & 0.0000 \\
delta2 & 0.053114 & 0.032543 & 1.632 & 0.1035 \\
Degrees of freedom & 2.318474 & 0.050431 & 45.97 & 0.0000 \\
No. Observations & 364 & No. Parameters & & 54 \\
No. Series & 6 & Log Likelihood & & 9026.822 \\
\hline
\end{tabular}

Source: Authors' work using OxMetrics 6.20

Table 6

Estimated Unconditional Volatility Matrix for EOS

\begin{tabular}{ccccccc}
\hline & eos & cac_40 & crobex & dax & $\begin{array}{c}\text { euro } \\
\text { next }\end{array}$ & smi \\
\hline eos & $\mathbf{0 . 1 0 0 0 2 4}$ & 0.017300 & 0.039136 & 0.001866 & 0.017795 & 0.026829 \\
cac_40 & 0.017300 & $\mathbf{0 . 0 0 5 5 3 9}$ & 0.363687 & 0.919521 & 0.981875 & 0.830200 \\
crobex & 0.039136 & 0.363687 & $\mathbf{0 . 0 0 3 8 3 6}$ & 0.301807 & 0.352478 & 0.314891 \\
dax & 0.001866 & 0.919521 & 0.301807 & $\mathbf{0 . 0 0 6 6 3 4}$ & 0.920555 & 0.821245 \\
euro & 0.017795 & 0.981875 & 0.352478 & 0.920555 & $\mathbf{0 . 0 0 5 2 7 9}$ & 0.852811 \\
next & 0.026829 & 0.830200 & 0.314891 & 0.821245 & 0.852811 & $\mathbf{0 . 0 0 5 6 4 4}$ \\
\hline smi & 0.0265 & & &
\end{tabular}

Source: Authors' work using OxMetrics 6.20

Due to a short research period, convergence problems arose in the case of ftse_100 and oil_brent, so these variables are not included. Values of lambda 2 parameters are small, indicating that the volatility reaction is not so sensitive to market movements or 
shocks on the market. At the same time, there is a strong persistence of volatility that takes a long time to disappear, as shown by the relatively high values of lambda 1 (above 0.9) (Jurić, 2014). The Swiss stock market index is an exception. The sum of lambda 1 and lambda 2 in all the variables in Table 5 is less than 1, thus satisfying the condition of stationarity, while the condition of non-negativity of the parameters is satisfied by the positive values of all lambda and delta.

As an implication from shocks to volatilities that are not permanent, investors and portfolio managers would have a higher chance of losing their money, even if they make a great profit in the short run. On the other hand, speculators welcome such conditions, which are favourable to their interests (Rahim et al., 2016). It can be inferred that it is safer to invest in any European stock market than in the cryptocurrency because EOS's unconditional volatility is approximately 20 times larger than in other variables.

Not a single index has a negative coefficient of unconditional correlation with the EOS cryptocurrency, which does not contribute to diversification. Although the coefficients are relatively small and close to zero, the EOS and indices relationship is slightly stronger than in other cryptocurrencies. The coefficients of the unconditional correlation between the indices are again very high. The strongest link exists between the French equity market and the Euronext index with a value of +0.981875 , which is not surprising since 64 French companies are part of that index. The remaining Western European markets are also highly correlated with the index as well as with each other. An estimate of the correlation of European markets with the Croatian capital market is in the range of +0.301807 to +0.363687 , which makes a weak but positive relationship. The Croatian stock index is again the least volatile, with an unconditional volatility coefficient of 0.003836 but has the highest coefficient of unconditional correlation with the studied cryptocurrency. Table 7 shows the estimation of the multivariate GARCH-DCC model with Ethereum.

Table 7

MGARCH-DCC Model for Ethereum with Underlying Student Distribution

\begin{tabular}{|c|c|c|c|c|}
\hline Parameter & Coefficient & Std. Error & t-value & Probability \\
\hline lambda1_cac_40 & 0.942264 & 0.026056 & 36.16 & 0.0000 \\
\hline lambda1_crobex & 0.895722 & 0.025995 & 34.46 & 0.0000 \\
\hline lambda1_dax & 0.958092 & 0.014279 & 67.10 & 0.0000 \\
\hline lambda1_euronext & 0.940709 & 0.023907 & 39.35 & 0.0000 \\
\hline lambda1_ftse_100 & 0.952970 & 0.052675 & 18.09 & 0.0000 \\
\hline lambda1_oil_brent & 0.980905 & 0.013807 & 71.04 & 0.0000 \\
\hline lambda1_smi & 0.940257 & 0.036772 & 25.57 & 0.0000 \\
\hline lambda2_cac_40 & 0.049478 & 0.033195 & 1.491 & 0.1365 \\
\hline lambda2_crobex & 0.053929 & 0.016421 & 3.284 & 0.0011 \\
\hline lambda2_dax & 0.035675 & 0.016787 & 2.125 & 0.0339 \\
\hline lambda2_euronext & 0.050481 & 0.029019 & 1.740 & 0.0823 \\
\hline lambda2_ftse_100 & 0.031711 & 0.025823 & 1.228 & 0.2198 \\
\hline lambda2_oil_brent & 0.014882 & 0.010757 & 1.383 & 0.1669 \\
\hline lambda2_smi & 0.040739 & 0.023196 & 1.756 & 0.0794 \\
\hline delta 1 & 0.762278 & 0.078493 & 9.711 & 0.0000 \\
\hline delta2 & 0.180423 & 0.051919 & 3.475 & 0.0005 \\
\hline Degrees of freedom & 2.221467 & 0.019147 & 116.0 & 0.0000 \\
\hline No. Observations & 843 & \multicolumn{2}{|c|}{ No. Parameters } & 79 \\
\hline No. Series & 8 & \multicolumn{2}{|c|}{ Log Likelihood } & 28207.056 \\
\hline
\end{tabular}

Source: Authors' work using OxMetrics 6.20 
The estimated model with Ethereum contains all eight-time series. Just like the previous estimations, the sum of the corresponding parameters is smaller than, but close to 1. Delta 1, or the estimated beta or GARCH term of the variable eth, is not as high as with btc or eos (0.762278), which indicates a somewhat weaker persistence of volatility that disappears faster than in the previously analysed cryptocurrencies. On the other hand, lambda 1 is exceptionally large in all other variables and exceeds 0.9. Table 8 presents unconditional volatility and correlation matrix.

Table 8

Estimated Unconditional Volatility Matrix for Ethereum

\begin{tabular}{|c|c|c|c|c|c|c|c|c|}
\hline & eth & cac_40 & crobex & dax & $\begin{array}{l}\text { euro } \\
\text { next }\end{array}$ & ftse_100 & $\begin{array}{c}\text { oil_ } \\
\text { brent }\end{array}$ & smi \\
\hline eth & 0.069679 & 0.009407 & 0.006218 & 0.008690 & 0.008890 & 0.008191 & 0.000699 & 0.012354 \\
\hline cac_40 & 0.009407 & 0.007737 & 0.699387 & 0.960668 & 0.993281 & 0.913636 & 0.702565 & 0.919362 \\
\hline crobex & 0.006218 & 0.699387 & 0.004205 & 0.681210 & 0.704919 & 0.687341 & 0.586694 & 0.659964 \\
\hline dax & 0.008690 & 0.960668 & 0.681210 & 0.007380 & 0.964430 & 0.892083 & 0.682133 & 0.927661 \\
\hline $\begin{array}{l}\text { euro } \\
\text { next }\end{array}$ & 0.008890 & 0.993281 & 0.704919 & 0.964430 & 0.006784 & 0.919935 & 0.708212 & 0.928944 \\
\hline ftse_100 & 0.008191 & 0.913636 & 0.687341 & 0.892083 & 0.919935 & 0.005251 & 0.719547 & 0.891606 \\
\hline $\begin{array}{c}\text { oil_ } \\
\text { brent }\end{array}$ & 0.000699 & 0.702565 & 0.586694 & 0.682133 & 0.708212 & 0.719547 & 0.012752 & 0.683669 \\
\hline smi & 0.012354 & 0.919362 & 0.659964 & 0.927661 & 0.928944 & 0.891606 & 0.683669 & 0.005721 \\
\hline
\end{tabular}

Source: Authors' work using OxMetrics 6.20

Ethereum is less volatile than EOS but more Bitcoin, with the unconditional volatility coefficient of 0.069679 . Correlation between indices and Ethereum is very weak, but in this case, it is positive. The French CAC 40 index shows an exceptionally strong correlation with all the other indices moving in the +0.913636 range with the FTSE 100 index to as much as +0.993281 with Euronext. The exception is Crobex with the coefficient +0.699387 , which is higher than in the Bitcoin model, but here a smaller sample was taken with only 843 observations.

Similarly, the French and the British, German and Swiss equity markets are characterized by strong integration, judging by the correlation coefficients that generally exceed the value of 0.9 , suggesting that it is not possible to diversify the portfolio by following the passive investment strategy in any two of the mentioned markets. Similar to the model with Ethereum, the GARCH model with Litecoin also contains all eight time series. Table 9 and Table 10 shows the results of the estimation of the mentioned model. 
Table 9

MGARCH-DCC Model for Litecoin with Underlying Student Distribution

\begin{tabular}{|c|c|c|c|c|}
\hline Parameter & Coefficient & Std. Error & t-value & Probability \\
\hline lambda1_cac_40 & 0.944911 & 0.025956 & 36.40 & 0.0000 \\
\hline lambda1_crobex & 0.888805 & 0.028649 & 31.02 & 0.0000 \\
\hline lambda1_dax & 0.958179 & 0.022539 & 42.51 & 0.0000 \\
\hline lambda1_euronext & 0.935831 & 0.031550 & 29.66 & 0.0000 \\
\hline lambda1_ftse_100 & 0.967413 & 0.030405 & 31.82 & 0.0000 \\
\hline lambda1_oil_brent & 0.968252 & 0.058770 & 16.48 & 0.0000 \\
\hline lambda1_smi & 0.904553 & 0.10775 & 8.395 & 0.0000 \\
\hline lambda2_cac_40 & 0.024410 & 0.013182 & 1.852 & 0.0645 \\
\hline lambda2_crobex & 0.066049 & 0.020590 & 3.208 & 0.0014 \\
\hline lambda2_dax & 0.027387 & 0.015211 & 1.800 & 0.0722 \\
\hline lambda2_euronext & 0.032424 & 0.017334 & 1.871 & 0.0618 \\
\hline lambda2_ftse_100 & 0.016146 & 0.012330 & 1.310 & 0.1908 \\
\hline lambda2_oil_brent & 0.018882 & 0.028221 & 0.6691 & 0.5037 \\
\hline lambda2_smi & 0.048927 & 0.046197 & 1.059 & 0.2899 \\
\hline delta 1 & 0.877894 & 0.031107 & 28.22 & 0.0000 \\
\hline delta2 & 0.091118 & 0.046850 & 1.945 & 0.0522 \\
\hline Degrees of freedom & 2.150429 & 0.015421 & 139.5 & 0.0000 \\
\hline No. Observations & 676 & \multicolumn{2}{|c|}{ No. Parameters } & 79 \\
\hline No. Series & 8 & \multicolumn{2}{|c|}{ Log Likelihood } & 23077.016 \\
\hline
\end{tabular}

Source: Authors' work using OxMetrics 6.20

Table 10

Estimated Unconditional Volatility Matrix for Litecoin

\begin{tabular}{ccccccccc}
\hline & Itc & cac_40 & crobex & dax & $\begin{array}{c}\text { euro } \\
\text { next }\end{array}$ & ftse_100 & $\begin{array}{c}\text { oil__ } \\
\text { brent }\end{array}$ & smi \\
\hline Itc & $\mathbf{0 . 0 8 2 4 1 6}$ & 0.012203 & 0.004012 & 0.013147 & 0.014523 & 0.016551 & 0.020275 & 0.028114 \\
\hline cac_40 & 0.012203 & $\mathbf{0 . 0 0 5 1 7 0}$ & 0.501579 & 0.925211 & 0.987708 & 0.846971 & 0.522527 & 0.849832 \\
crobex & 0.004012 & 0.501579 & 0.004502 & 0.480850 & 0.512011 & 0.502511 & 0.293934 & 0.469911 \\
\hline dax & 0.013147 & 0.925211 & 0.480850 & 0.005732 & 0.928907 & 0.811115 & 0.471593 & 0.844687 \\
euro & 0.014523 & 0.987708 & 0.512011 & 0.928907 & 0.004772 & 0.864623 & 0.527395 & 0.866243 \\
next & 0.016551 & 0.846971 & 0.502511 & 0.811115 & 0.864623 & 0.004587 & 0.547920 & 0.829955 \\
ftse_100 & 0.016535 \\
$\begin{array}{c}\text { oil_ } \\
\text { brent }\end{array}$ & 0.020275 & 0.522527 & 0.293934 & 0.471593 & 0.527395 & 0.547920 & 0.012381 & 0.475397 \\
smi & 0.028114 & 0.849832 & 0.469911 & 0.844687 & 0.866243 & 0.829955 & 0.475397 & $\mathbf{0 . 0 0 5 1 1 7}$ \\
\hline
\end{tabular}

Source: Authors' work using OxMetrics 6.20

In the fourth model, again, no index has a negative coefficient of unconditional correlation with cryptocurrencies, which does not diversify the portfolio. Coefficients are relatively low and close to zero, but the Litecoin and index correlations are slightly stronger than those of Bitcoin and Ethereum and are in a range similar to EOS. Remaining elements correspond to the values shown in previous cryptocurrencies, which confirms the validity of the model estimation.

Unlike the models' estimations for Bitcoin, EOS, Ethereum, and Litecoin, Engle's multivariate GARCH-DCC model was not the appropriate solution for Ripple because stationarity and non-negativity criteria were not met. Therefore, the last estimated is an IGARCH model that is characterized by a persistent variance, meaning that the information from the current period remains relevant for forecasting contingency variance in all subsequent periods. It is a necessary condition for the IGARCH model that the sum of lambda 1 and lambda 2 amounts to 1. According to the results in Table 
11, the condition is fulfilled for all variables. There is no information on standard error and t-values for betas, i.e., GARCH terms.

Table 11

IGARCH Model for Ripple with Underlying Student Distribution

\begin{tabular}{lllll}
\hline Parameter & Coefficient & Std. Error & †-value & Probability \\
\hline lambda1_cac_40 & 0.953450 & - & - & - \\
lambda1_crobex & 0.911276 & - & - & - \\
\hline lambda1_euronext & 0.947874 & - & - & - \\
\hline lambda1_ftse_100 & 0.964749 & - & - & - \\
lambda1_oil_brent & 0.954913 & - & - & - \\
lambda1_smi & 0.950754 & - & - & - \\
\hline lambda2_cac_40 & 0.046550 & 0.023596 & 1.973 & 0.0487 \\
lambda2_crobex & 0.088724 & 0.020518 & 4.324 & 0.0000 \\
lambda2_euronext & 0.052126 & 0.022710 & 2.295 & 0.0219 \\
lambda2_ftse_100 & 0.035251 & 0.019699 & 1.790 & 0.0738 \\
lambda2_oil_brent & 0.045087 & 0.037842 & 1.191 & 0.2337 \\
lambda2_smi & 0.049246 & 0.020125 & 2.447 & 0.0145 \\
delta1 & 0.909437 & - & - & - \\
delta2 & 0.090563 & 0.024986 & 3.624 & 0.0003 \\
Degrees of freedom & 2.123409 & 0.011198 & 189.6 & 0.0000 \\
No. Observations & 1247 & No. Parameters & 59 \\
No. Series & 7 & Log Likelihood & & 34931.599 \\
\hline
\end{tabular}

Source: Authors' work using OxMetrics 6.20

Ripple demonstrates a large potential for increasing portfolio efficiency because of negative link with the other variables. It should be emphasized that Ripple is the only one of the analysed cryptocurrencies that has a negative correlation with Crobex, which means that the Croatian investors would thus achieve a mild diversification of the portfolio.

Table 12

Estimated Unconditional Volatility Matrix for Ripple

\begin{tabular}{cccccccc}
\hline & xrp & cac_40 & crobex & $\begin{array}{c}\text { euro } \\
\text { next }\end{array}$ & ftse_100 & $\begin{array}{c}\text { oil__ } \\
\text { brent }\end{array}$ & smi \\
\hline xrp & $\mathbf{0 . 1 8 0 3 8 8}$ & -0.006814 & -0.015667 & -0.009408 & -0.012036 & -0.019006 & -0.002402 \\
\hline cac_40 & -0.006814 & $\mathbf{0 . 0 1 1 7 1 1}$ & 0.522795 & 0.994783 & 0.901546 & 0.460254 & 0.892529 \\
$\begin{array}{c}\text { crobex } \\
\text { euro }\end{array}$ & -0.015667 & 0.522795 & $\mathbf{0 . 0 0 3 8 9 3}$ & 0.528004 & 0.502903 & 0.332969 & 0.471157 \\
$\begin{array}{c}\text { next } \\
\text { ftse_100 }\end{array}$ & -0.009408 & 0.994783 & 0.528004 & $\mathbf{0 . 0 1 0 8 9 7}$ & 0.910451 & 0.465241 & 0.897093 \\
$\begin{array}{c}\text { oil_ } \\
\text { brent }\end{array}$ & -0.019006 & 0.460254 & 0.332969 & 0.465241 & 0.486969 & $\mathbf{0 . 0 1 6 8 6 3}$ & 0.433598 \\
smi & -0.002402 & 0.892529 & 0.471157 & 0.897093 & 0.868889 & 0.433598 & $\mathbf{0 . 0 0 7 2 2 2}$ \\
\hline
\end{tabular}

Source: Authors' work using OxMetrics 6.20

However, it is essential to point to Ripple's unconditional volatility coefficient, which in the observed period amounts to as much as 0.180388 , which is approximately 2.5 times higher than in the other cryptocurrencies, or a 46.3 times higher volatility than Crobex, which is the least volatile index. That is why it is unlikely that investors in the Croatian (and European) market will use cryptocurrencies as a diversification tool. 


\section{Continuous Wavelet Transform}

The results of the analysis are shown in Figures 2-6. Depending on the amount of data available, scales of 1 (2-4 days) to 8 (512 days) are used. Scale up to 8 was used only in Bitcoin, while in Ripple and Ethereum it went up to 7, Litecoin up to 6 and EOS up to 5. The $x$-axis represents the time expressed in days, and the $y$-axis represents the investment horizon. The $5 \%$ significance level values, which are estimated by the Monte Carlo simulation, are shown in a curved line on the graphs. Values outside the curved line are not significant for the study.

Leftwards arrows indicate a negative correlation, while the rightwards arrows show a positive correlation between the observed variables. Furthermore, the North East and arrows indicate that cryptocurrencies are lagging. The South West arrow indicates that the first variable leads the other. The North West arrow indicates that the first variable lags the second one, and the South East arrow means the first variable leads the other (Madaleno and Pinho, 2012).

The hotter the colour is (in this case yellow), the higher the correlation. The matching of colours and correlation levels is represented by the scale on the right hand side of each CWT graph. On the other hand, the colder colour, or bluer one, indicates less correlation in that period (Kristoufek, 2015).

Figure 2

Continuous Wavelet Transform for Bitcoin
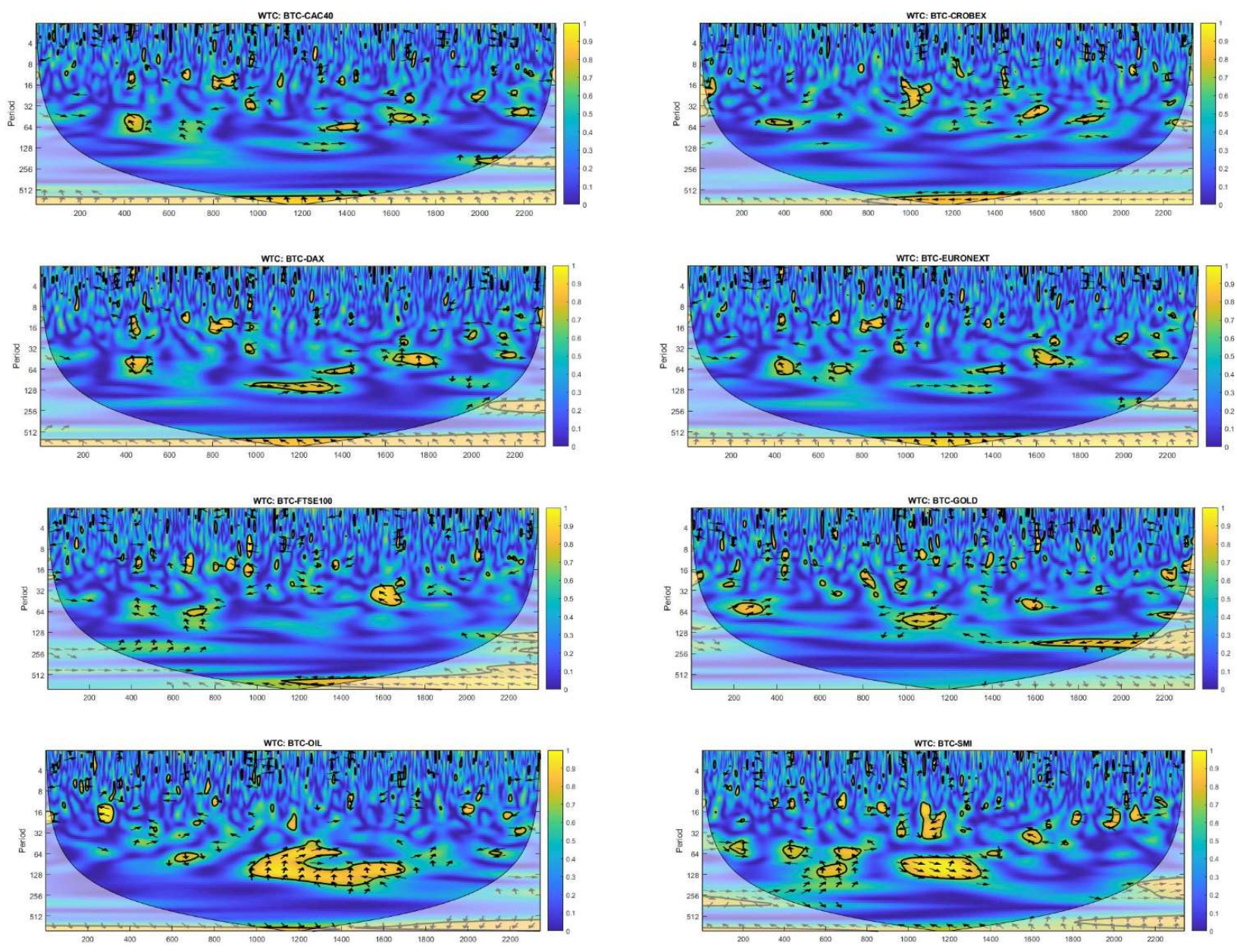

Source: Authors' work using MATLAB R2017b 
Figure 2 shows a weak coherence between Bitcoin and the observed independent variables due to the dominant blue colour. In addition to the initial period, scale 1 (24 days), where the yellow dominates, some higher yellow signals can be seen only in the SMI and OIL indices indicating a high correlation with Bitcoin in the 64-128 day investment period and time period around 1000 to 1400 th day. These graphs point to great diversification possibilities that investing in Bitcoin offers. The most prominent negative correlation is shown on the graph with gold, proxy where the most arrows are facing left.

Figure 3

Continuous Wavelet Transform for EOS
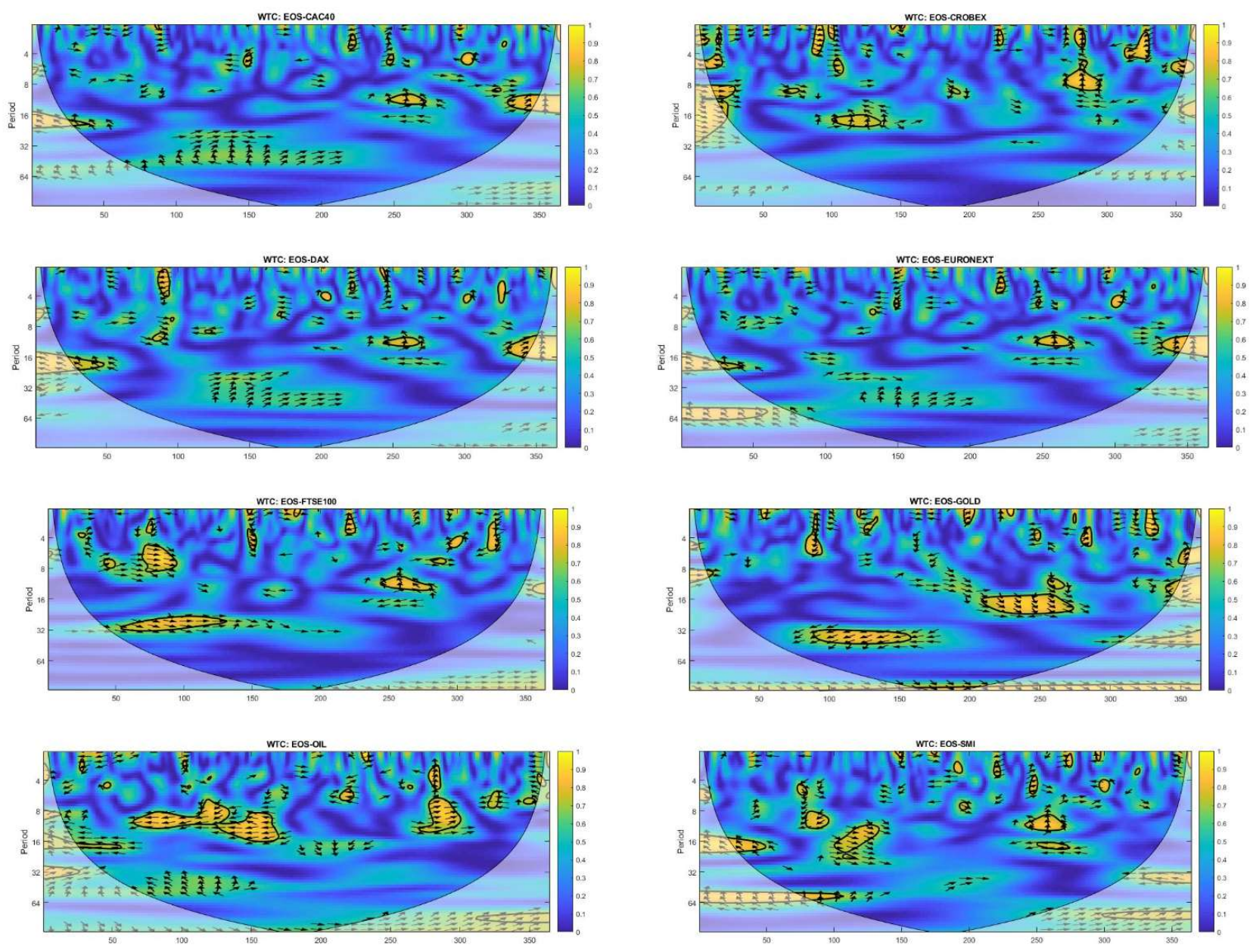

Source: Authors' work using MATLAB R2017b

Figure 3 illustrates the coherence of EOS, which has the shortest research period and the domination of the blue colour. The dominance of leftwards arrows, or arrows indicating a negative correlation, can be seen in the graph with oil proxy. Significant signals can be observed in the investment period between 8 and 32 days for four variables - ftse 100, gold, oil, and smi. In the first four graphs, the domination of blur shows the diversification potential that EOS provides for individual portfolios.

Figure 4 for Ethereum, also shows domination of the blue colour. The only significant signals can be observed in the oil_brent and crobex variables, for the investment period between 32 and 64 days and the time period around 400 days. These two variables actually contain the most yellow colour, while the other variables are highly 
dominated by the previously mentioned blue colour. Therefore, Ethereum may be a less useful diversification instrument.

\section{Figure 4}

Continuous Wavelet Transform for Ethereum
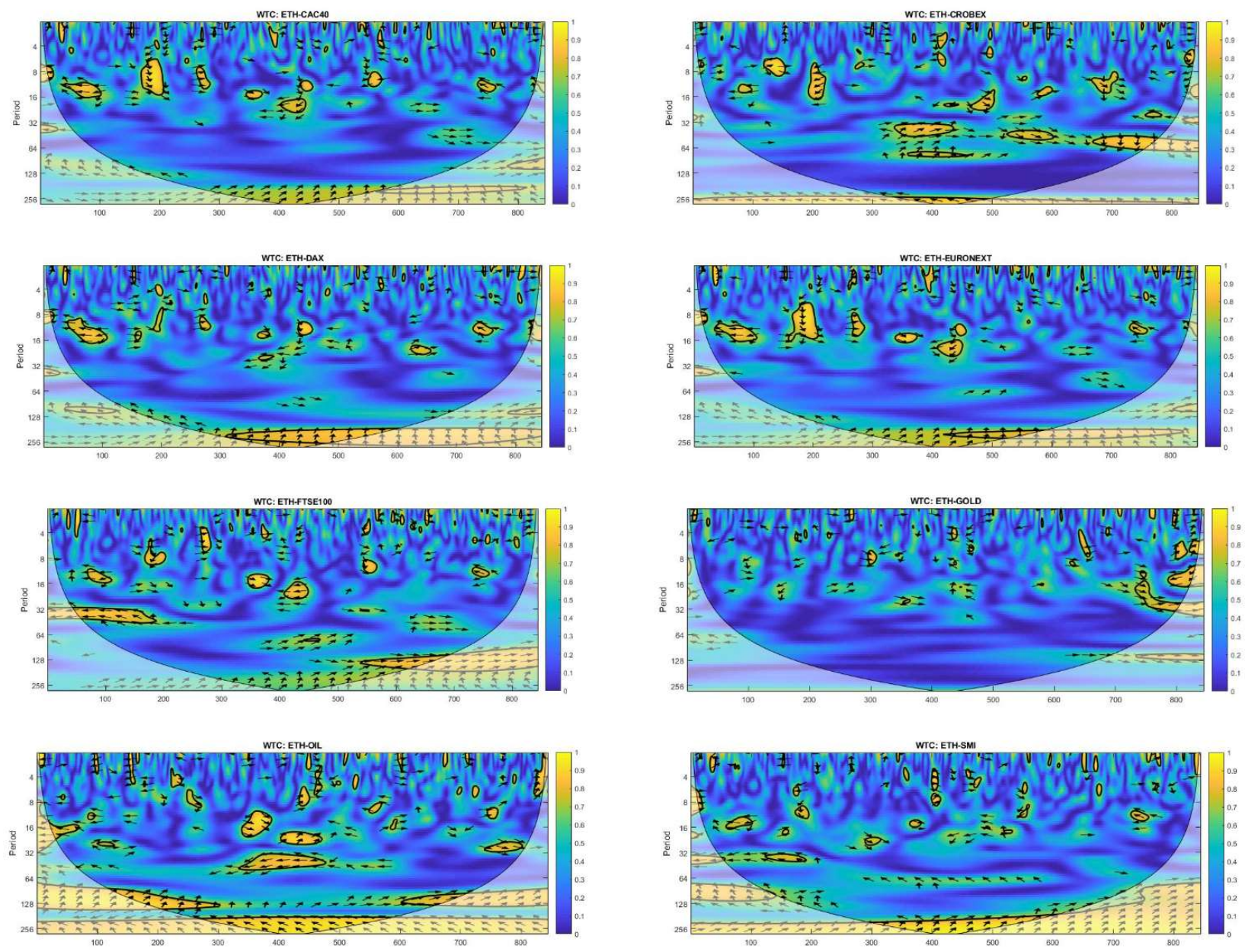

Source: Authors' work using MATLAB R2017b

In Figure 5, colour blue points to low levels of coherency between Litecoin and indices. The domination of the yellow colour, which is shown in the investment period of 16-32 days and the time period of about 200 to 250 days. Arrows pointing to the left show the negative correlation of Litecoin with most observed variables. It is obvious that the most dominant yellow colour is in the Crobex graph, at the 64-128 day investment period and the time period from 1 to 200 days. However, most of that yellow "island" is beneath a curved line that indicates a space that is not statistically significant for interpretation. 
Figure 5

Continuous Wavelet Transform for Litecoin
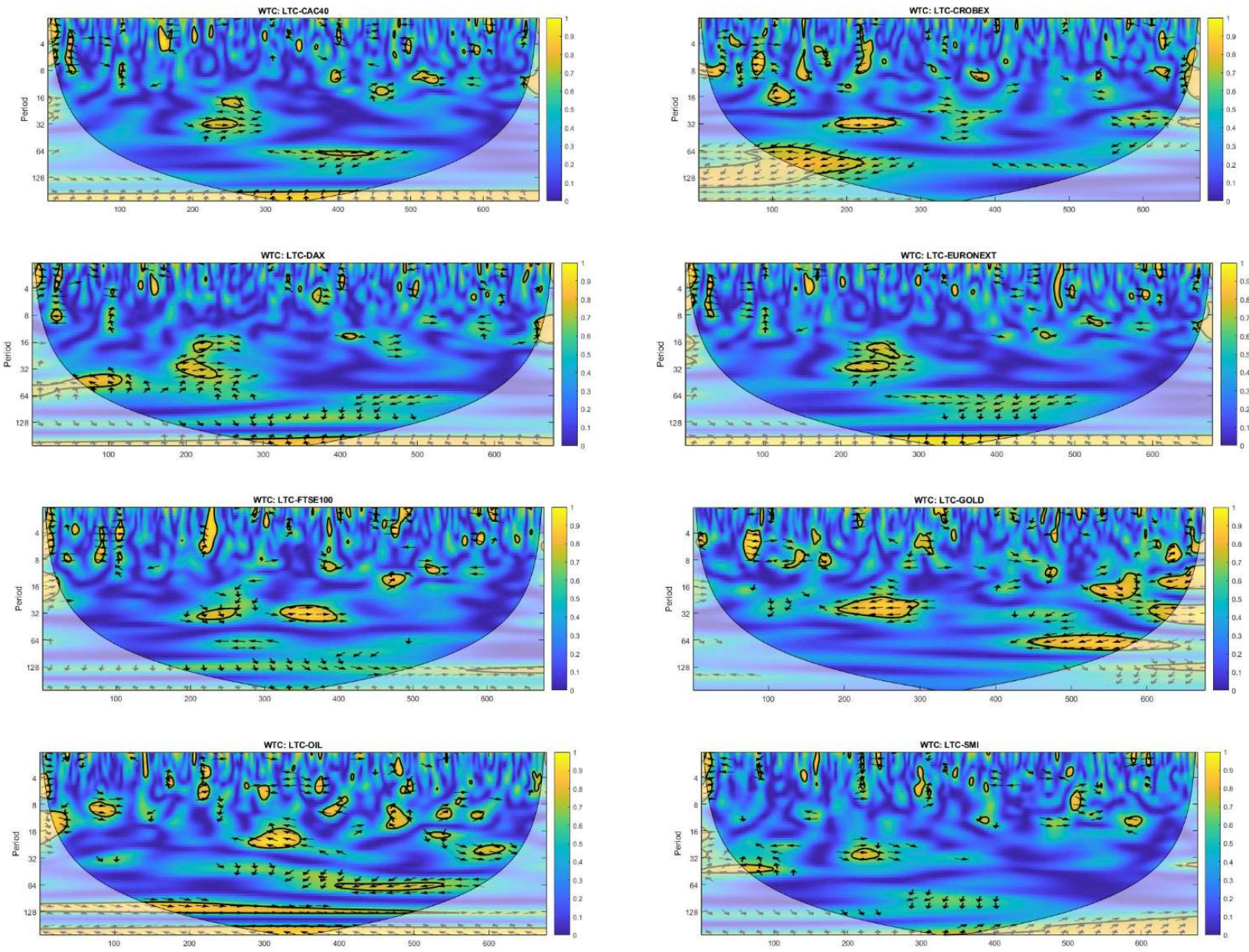

Source: Authors' work using MATLAB R2017b

In Figure 6, a weak link between Ripple and the observed variables can be established. The only period with significant signals is the investment period between 128 to 256 days and the time period of 600 to 700 days. It is important to point out that the above mentioned significant correlation is visible on virtually all lower-right corner displays except the FTSE 100 index and the gold proxy. From this, one can conclude that Ripple is not as good diversification tool for longer investment periods as other cryptocurrencies. 
Figure 6

Continuous Wavelet Transform for Ripple
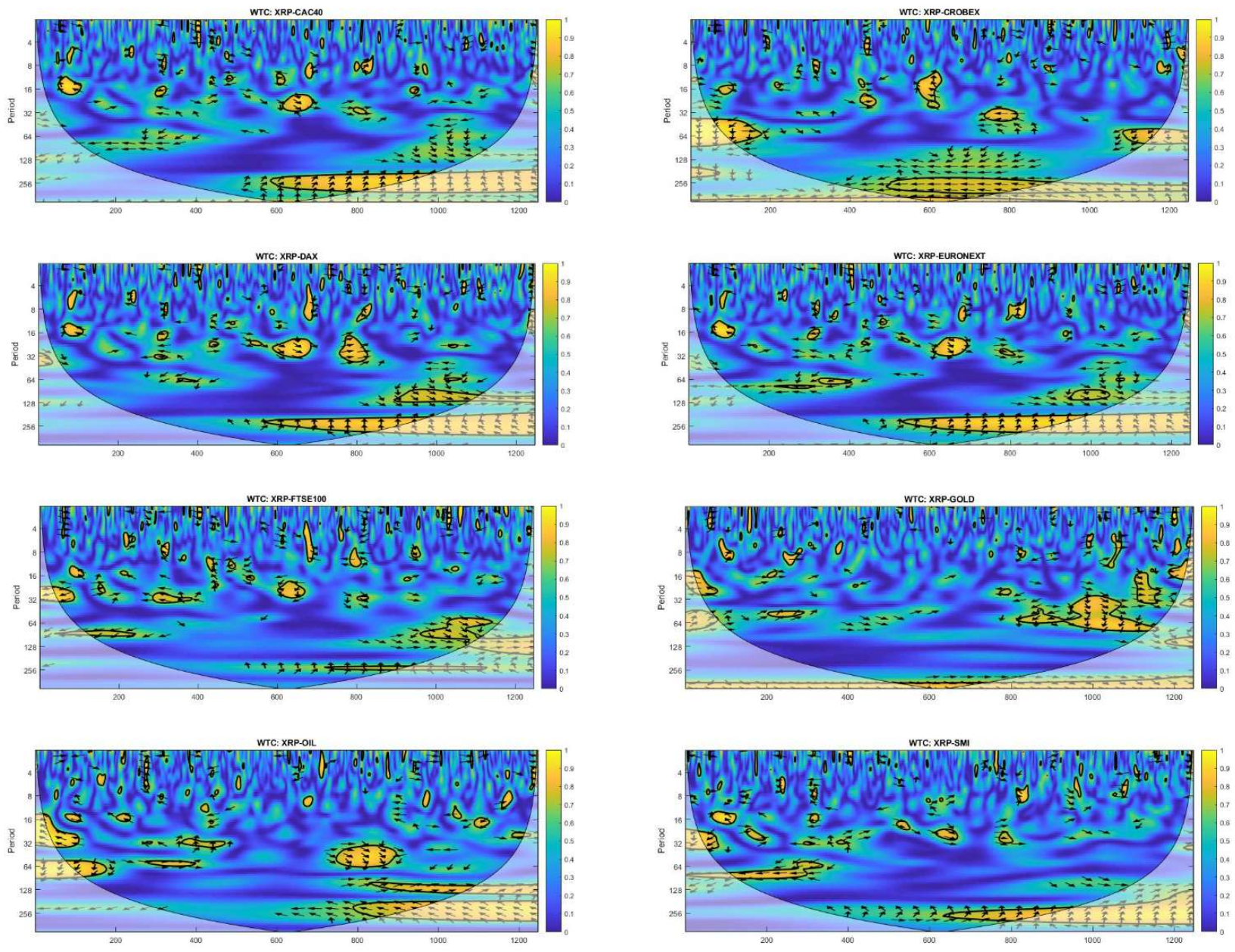

Source: Authors' work using MATLAB R2017b

In addition to the specially highlighted and explained portions of these graphic representations with a more dominant yellow colour, there are no significant periods indicating a high level of correlation between the observed independent variables with cryptocurrencies. Finally, it can be concluded that longer investment periods point to lower, mostly negative, correlation levels for virtually all observed indices. In other words, it can be concluded that cryptocurrencies have the ability to diversify the portfolios for different investors on European markets, given the investment period. Of course, it is important to mention that cryptocurrencies' values are unpredictable compared to the observed market indices. As such investments, cryptocurrencies could make a useful diversification tool but should be used with a precaution. As mentioned above, all major financial institutions warn about the potential dangers of investing in them. Therefore, cryptocurrencies have the ability to offset bad trends in European markets but are certainly not stable enough to be relied upon by investors for achieving portfolio diversification.

\section{Conclusion}

For the purpose of examining the possibilities of diversification in selected European markets using cryptocurrencies, extensive econometric analysis has been carried out, 
divided into two steps. The first part of the empirical analysis includes the estimation of the multivariate GARCH-DCC model, and the second part refers to the Continuous Wavelet Transform. MGARCH-DCC model enables accurate analysis of precise timings of a shift in conditional correlations and volatilities. In the first step, parameters of univariate volatility are estimated, while in the second step, unconditional volatility matrices are obtained, which reveal if the use of virtual currencies for portfolio diversification is justified. Two cryptocurrencies, Bitcoin and Ripple, have proved to be a possible diversification instrument for most of the observed European markets, given that coefficients of unconditional correlation were negative. The GARCH model estimations were checked using the Wavelet transformation, whereby the portfolio diversification effect was tested at different time periods. This method provides a more extensive representation of time-frequency analysis and can study the transition dynamics of the two time series, using the Monte Carlo simulation. Wavelet transformation partly confirms the results of the estimated multivariate GARCH-DCC models. The link between the value of the cryptocurrencies and the selected indices is mostly very weak and negative, which suggests that some cryptocurrencies can serve as a mild diversification tool, while some markets showed no connections to cryptocurrencies at all. However, due to their extremely high volatility, which is in some periods up to 50 times higher than the volatility of the observed indices, cryptocurrencies make a high-risk investment, and a means that cannot be relied upon to a great extent.

In the end, it should be noted that this study was carried out on a small sample of selected European countries. Further research could focus on a greater number of economies (such as transition countries) or a different set of financial indicators, as well as on providing a more in-depth analysis of the dynamics between cryptocurrencies and capital market indicators. Lastly, future studies could fruitfully explore the possibilities for diversification by using portfolio constructing tools, such as portfolio backtesting, to infer whether cryptocurrencies could advance portfolio efficiency.

\section{References}

1. Arnerić J. (2007), "Ekonometrijsko modeliranje rizika na hrvatskom tržištu kapitala" (Econometric approach to risk modelling at Croatian capital market), Master's Thesis, Zagreb, Faculty of Economics and Business.

2. Bauwens, L., Laurent, S., Rombouts, J. V. K. (2006), "Multivariate GARCH models: A survey", Journal of Applied Econometrics, Vol. 21, No. 1, pp. 79-109.

3. Bouri, E., Jalkh, N., Molnár, P., Roubaud, D. (2017a), "Bitcoin for energy commodities before and after the December 2013 crash: diversifier, hedge or safe haven?", Applied Economics, Vol. 49, No. 50, pp. 5063-5073.

4. Bouri, E., Molnár, P., Azzi, G., Roubaud, D., Hagfors L. I. (2017b), "On the hedge and safe haven properties of Bitcoin: Is it really more than a diversifier?", Finance Research Letters, Vol. 20, pp. 192-198.

5. Bouri, E., Gupta, R., Tiwari, A. K., Roubaud, D. (2017c), "Does Bitcoin hedge global uncertainty? Evidence from Wavelet-based quantile-in-quantile regressions", Finance Research Letters, Vol. 23, pp. 87-95.

6. Brière, M., Oosterlinck, K., Szafarz, A. (2015), "Virtual currency, tangible return: Portfolio diversification with Bitcoin", Journal of Asset Management, Vol. 16, No. 6, pp. 365-373.

7. Cermak, V. (2017), "Can Bitcoin Become a Viable Alternative to Fiat Currencies? An Empirical Analysis of Bitcoin's Volatility Based on a GARCH Model", available at: https://papers.ssrn.com/sol3/papers.cfm?abstract_id=2961405 (19 August 2018).

8. Chu, J., Chan, S., Nadarajah, S., Osterrieder, J. (2017), "GARCH Modelling of Cryptocurrencies", Journal of Risk and Financial Management, Vol. 10, No. 4. 
9. CNN Money Stock Market Data (N/A), available at: https://money.cnn.com/data/markets (18 August 2018).

10. Croatian Financial Services Supervisory Agency (N/A), "Capital market", available at: https://www.hanfa.hr/trziste-kapitala/ (20 August 2018).

11. Dhyrberg, A. H. (2015), "Hedging Capabilities of Bitcoin. Is it the virtual gold?", available at: https://researchrepository.ucd.ie/handle/10197/7169 (19 August 2018).

12. Eisl, A., Gasser, S. M., Weinmayer, K. (2015), "Caveat emptor: Does Bitcoin improve portfolio diversification?", available at:

https://papers.ssrn.com/sol3/papers.cfm?abstract_id=2408997 (18 August 2018).

13. Engle, R. F. (2002), "Dynamic Conditional Correlation: A Simple Class of Multivariate Generalized Autoregressive Conditional Heteroskedasticity Models", Journal of Business \& Economic Statistics, Vol. 20, No. 3, pp. 339-350.

14. Engle, R. F., Sheppard, K. (2001), "Theoretical and Empirical properties of Dynamic Conditional Correlation Multivariate GARCH", NBER Working Paper 8554, National Bureau of Economic Research.

15. ESMA (2018), "ESMA, EBA, and EIOPA warn consumers on the risks of Virtual Currencies", available at: https://www.esma.europa.eu/press-news/esma-news/esas-warn-consumersrisks-in-buying-virtual-currencies (18 August 2018).

16. European Central Bank (2012), "Virtual Currency Schemes", available at: http://www.ecb.int/pub/pdf/other/virtualcurrencyschemes201210en.pdf (18 August 2018).

17. European Central Bank (2018), available at: https://www.ecb.europa.eu/home/html/index.en.html (20 August 2018).

18. European Commission (2018), available at https://ec.europa.eu/ (20 August 2018).

19. Hajba, M. (2009), "Wavelet (valić) transformacija" (Wavelet Transform), Hrvatski matematički elektronički časopis (math.e), Vol. 28, available at: http://e.math.hr/vol28/Hajba (17 August 2018).

20. Halaburda, H., Gandal, N. (2016), "Competition in the Cryptocurrency Market", NET Institute Working Paper, pp. 14-17.

21. Hayes, A. (2015), "The Decision to Produce Altcoins: Miners' Arbitrage in Cryptocurrency Markets", The New School for Social Research Working Paper, 04/2015.

22. Jurić, M. (2014), "Analiza optimalnog portfelja odabranih dionica na hrvatskom tržištu kapitala GARCH modelom" (Analysis of the Optimal Portfolio of Selected Stocks on the Croatian Capital Market Using GARCH Model), Graduate Thesis, Zagreb, Faculty of Economics and Business.

23. Katsiampa, P. (2017), "Volatility estimation for Bitcoin: A comparison of GARCH models", Economics Letters, Vol. 158, pp. 3-6.

24. Kristoufek, L. (2015), "What Are the Main Drivers of the Bitcoin Price?, Evidence from Wavelet Coherence Analysis", PLoS ONE, Vol. 10, No. 4.

25. Lim, S. J., Masih, M. (2017), "Exploring portfolio diversification opportunities in Islamic capital markets through bitcoin: evidence from MGARCH-DCC and Wavelet approaches", MPRA Paper, 79752.

26. Madaleno, M., Pinho, C. (2012), "International stock market indices comovements: a new look", International Journal of Finance \& Economics, Vol. 17, No. 1, pp. 89-102.

27. Penrose, K. L. (2014), "Banking on Bitcoin: Applying Anti-Money Laundering and Money Transmitter Laws", North Carolina Banking Institute, Vol. 18, pp. 529-551.

28. Poyser, O. (2017), "Exploring the determinants of Bitcoin's price: an application of Bayesian Structural Time Series", Ph.D. Thesis, New York: Cornell University.

29. Rahim, A. M., Masih, M. (2016), "Portfolio diversification benefits of Islamic investors with their major trading partners: Evidence from Malaysia based on MGARCH-DCC and wavelet approaches", Economic Modelling, Vol. 54, pp. 425-438.

30. Stavroyiannis, S., Babalos V. (2017), "Dynamic properties of the Bitcoin and the US market", available at: https://papers.ssrn.com/sol3/papers.cfm?abstract_id=2966998

(20 August 2018). 
31. Tillier, M. (2015), "Accept That Bitcoin is a Currency and Stop Blaming the Victims of Crime", NASDAQ, available at: http://www.nasdaq.com/article/accept-that-bitcoin-is-acurrency-and-stopblaming-the-victims-of-crime-cm442726 (21 August 2018).

32. Tse, Y. K., Tsui, A. K. C. (2002), "A Multivariate GARCH Model with Time-Varying Correlations", Journal of Business and Economic Statistics, Vol. 20, No. 3, pp. 351-362.

33. Urquhart, A. (2017), "The volatility of Bitcoin", available at:

https://papers.ssrn.com/sol3/papers.cfm?abstract_id=2921082 (20 August 2018).

34. Velde, F. R. (2013), "Bitcoin: A primer", The Federal Reserve Bank of Chicago, available at: https://www.chicagofed.org/ /media/publications/chicago-fed-

letter/2013/cfldecember2013-317-pdf.pdf (20 August 2018).

\section{About the authors}

Ana Pavković is a Teaching and Research Assistant at the Faculty of Economics and Business, University of Zagreb, Department of Economic Theory. She is currently enrolled in the University Postgraduate (Doctoral) Study Programme. She won Award for the Best Paper on Insurance in 2015, Dean's Award for the Best Undergraduate Thesis in 2015 and Rector's Award in 2016. Her main research interests include applied financial econometrics, insurance, and pension systems. The author can be contacted at ana.pavkovic@efzg.hr.

Mihovil Anđelinović, Ph.D. is an Assistant Professor at the Faculty of Economics and Business, University of Zagreb, Department of Finance. He received a Ph.D. in Finance at the University of Split, Faculty of Economics with the dissertation thesis "The Impact of Economic Cycles on Insurance Company's Investment Portfolio Structure". His main research interests are capital markets, bank systems, insurance, pension funds, and risk management. The author can be contacted at mandelinovic@efzg.hr.

Ivan Pavković is a Graduate Student at the Faculty of Economics and Business, University of Zagreb, pursuing a Master's degree in Finance. Aside from finance, he is greatly interested in new technologies, such as cryptocurrencies, a breakthrough in traditional forms of payments. His main research interests include financial markets and investment analysis. In his spare time, he is a digital marketing freelancer who works with clients worldwide. The author can be contacted at ipavkovic7@hotmail.com. 